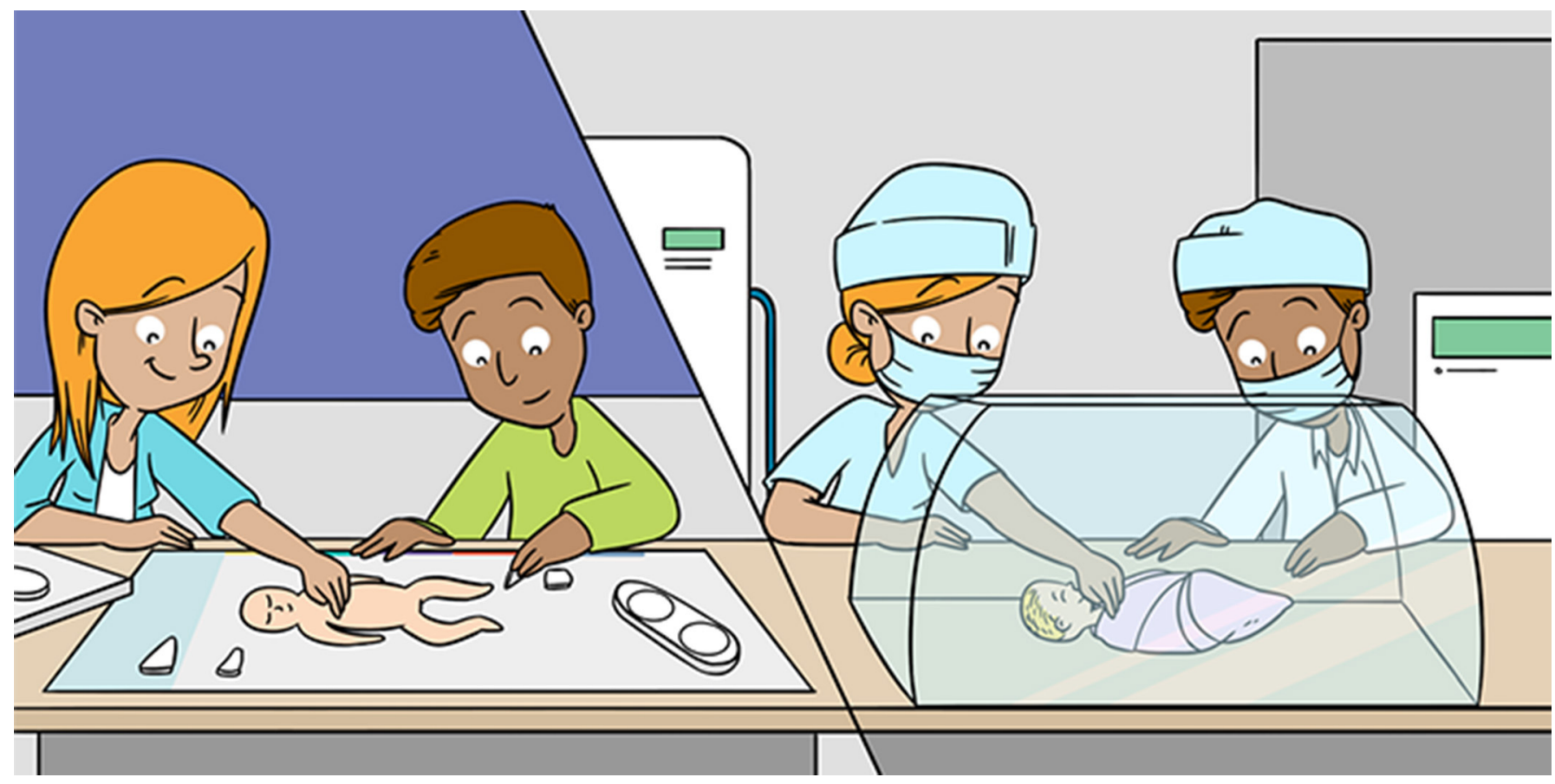

\title{
USING GAMES TO TRAIN DOCTORS AND NURSES TO SAVE BABIES AT BIRTH
}

\section{Simran K. Ghoman ${ }^{1,2}$ and Georg M. Schmölzer ${ }^{1,2^{*}}$}

${ }^{1}$ Neonatal Research Unit, Centre for the Studies of Asphyxia and Resuscitation, Royal Alexandra Hospital, Edmonton, AB, Canada ${ }^{2}$ Department of Pediatrics, Faculty of Medicine and Dentistry, University of Alberta, Edmonton, AB, Canada

\section{YOUNG REVIEWER:}

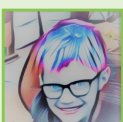

EDWARD

AGE: 12
For parents, the sound of their newborn baby crying is a wonderful sign that the baby is healthy and breathing. However, millions of babies each year are born sick and depend on doctors and nurses to help them start breathing. Helping a baby breathe is called neonatal resuscitation. It is important that doctors and nurses practice performing the correct steps of neonatal resuscitation so that they are ready when a newborn baby needs their help. We created the boardgame RETAIN for doctors and nurses to play, to train their neonatal resuscitation knowledge and skills. We discovered that doctors and nurses significantly improved their knowledge of neonatal resuscitation after playing RETAIN. Building on this discovery, we may be able to use RETAIN to help doctors and nurses all around the world be better prepared to save babies at birth.

\section{INTRODUCTION}

When babies are born, they announce themselves with a cry. This crying shows that the babies are taking their first breaths. A baby 
NEONATAL

\section{RESUSCITATION}

Helping babies breathe at birth.

\section{SIMULATION}

Creating a safe environment by replicating real-world situations, to teach learners what they will be expected to know and do during their jobs. crying at birth is the most wonderful sound in the world to the parents! The crying of a baby at birth is heard around 130 million times a year all around the world. Sadly, 13-26 million babies are sick when they are born, and do not cry. They need urgent help from doctors and nurses. Helping a baby to breathe at birth is called neonatal resuscitation.

\section{WHAT IS NEONATAL RESUSCITATION?}

Neonatal resuscitation is a special type of first aid for newborn babies. During neonatal resuscitation, doctors, and nurses must complete a series of steps to help the baby breathe. These steps include:

- Warmth, to keep the baby's body temperature safe and comfortable

- Stimulation (rubbing the body) to wake the baby up and remind the baby to breathe

- Extra oxygen to help the baby to breathe

- Breaths through a mask placed over the baby's mouth and nose

- Chest compressions (pumping the baby's chest) to help keep the heart beating

- Medicine to help the baby's heart start beating again.

\section{WHY IS TRAINING FOR NEONATAL RESUSCITATION SO IMPORTANT?}

Doctors and nurses work together to help newborn babies as they enter the world. It is important that doctors and nurses are always prepared to perform neonatal resuscitation. Being part of a neonatal resuscitation team is like being on a sports team. In sports, each teammate must practice individually by exercising, learning drills, watching games, and listening to the coach. But it is also important that the team practices playing together during scrimmages, so that everyone learns how to work together to win a real game. Neonatal resuscitation is not so different. Team members must practice individually, to better their individual knowledge and skills, as well as practice together as a team. This combination of training individually and together best prepares doctors and nurses to save a newborn baby's life.

\section{HOW DO DOCTORS AND NURSES TRAIN FOR NEONATAL RESUSCITATION?}

To practice their knowledge and skills, doctors and nurses attend classes, read textbooks, or participate in simulated neonatal resuscitations. During a simulation, doctors and nurses use equipment and supplies to perform neonatal resuscitation on a doll that looks like a real baby, in a classroom that looks like a real delivery room. 
An instructor, like a coach, leads the simulation and lets everyone know what they are doing well, and how they can improve. Training together during simulation is the best way to prepare for real-life neonatal resuscitation.

It is important that doctors and nurses train often, so that they do not make mistakes. However, doctors and nurses are very busy taking care of many patients, so they often do not have time to train as frequently as they should. When training is infrequent, they can forget how to perform neonatal resuscitation, which can be harmful for the baby. While simulation is a great way to train, it can also be expensive to use simulation to train doctors and nurses as often as they should be trained. As with all expensive things, not everyone can afford simulations and therefore not all doctors and nurses around the world will be able to use this method to practice neonatal resuscitation. Therefore, we need a new approach to train doctors and nurses in neonatal resuscitation.

\section{COULD WE USE GAMES TO TRAIN INSTEAD?}

To make training more available and less expensive, we developed a simulation-based board game to teach neonatal resuscitation. Many people enjoy playing games, because games are fun and exciting, captivate our emotions, and stimulate our determination to win, which motivates us to play. Games can also help us learn. Games that teach us something while we play are called serious games. Serious games can be designed to teach us information or skills that may be useful for our schoolwork or jobs. Because games are fun to play, we are motivated to learn and practice even more (this is called game-based learning).

We thought that a serious game might help doctors and nurses to train for neonatal resuscitation. We worked with a team of doctors, educators, designers, and scientists to create the board game RETAIN. RETAIN combines simulation-based training with game-based learning, to help healthcare workers practice neonatal resuscitation knowledge and skills.

\section{WHAT IS THE RETAIN GAME?}

RETAIN is a fun way to practice neonatal resuscitation as a team, and busy doctors and nurses can play RETAIN anytime and anyplace. During the game, players review the medical history of an imaginary baby, which will help them to prepare for the situation. Once the baby is born, doctors and nurses have to work as a team using action cards (which represent different tasks, like measuring the baby's heart rate) and 3D-equipment pieces (like a face mask to give oxygen). There is also a facilitator, a player who will provide the team with information about the baby's health (like the baby's heart rate). This will help the 
Figure 1

Doctors and nurses use the RETAIN board game to practice their neonatal resuscitation knowledge and skills together as a team.

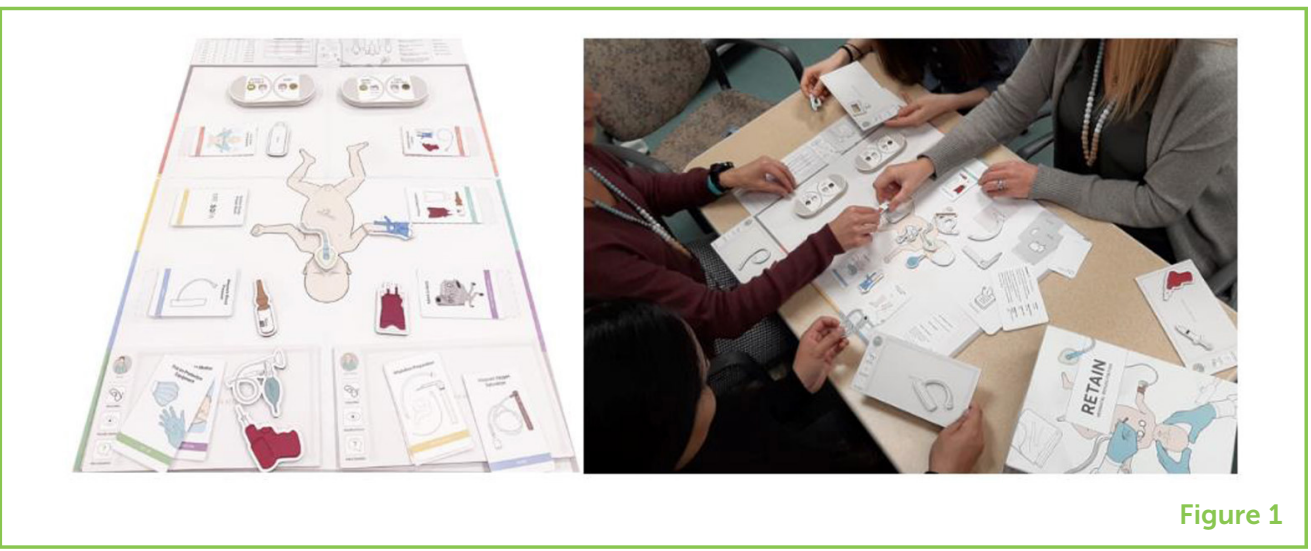

team know how the baby is doing throughout the scenario. Players win the game once the baby is breathing (Figure 1).

\section{HOW CAN WE KNOW IF RETAIN ACTUALLY WORKS?}

Before doctors and nurses can use RETAIN to train for neonatal resuscitations, it is important to study whether playing RETAIN actually improves neonatal resuscitation knowledge and skills. To do this, we went to a hospital where around 6,500 babies are born every year. We asked the doctors and nurses there to participate in our study. At the start of the study, doctors and nurses took a test on what they knew about neonatal resuscitation (this was called the pre-test). After the pre-test, the doctors and nurses played the RETAIN board game. After playing the game for $30 \mathrm{~min}$, they took another test to see how much their neonatal resuscitation knowledge improved (this was called the post-test).

\section{WHAT DID WE DISCOVER?}

Doctors and nurses scored much higher on the post-test than on the pre-test, meaning that they improved their knowledge of neonatal resuscitation after playing RETAIN. After playing the RETAIN board game only once, these experienced doctors and nurses improved their knowledge of the correct steps of neonatal resuscitation by $12 \%$ (Figure 2). Our participants were already very knowledgeable about neonatal resuscitation (with an average of 7.5 years of experience taking care of newborn babies) and only played RETAIN for a short time (about $30 \mathrm{~min}$ ). So, it was really exciting to see an improvement in their neonatal resuscitation knowledge during our study. Doctors and nurses also enjoyed RETAIN, with $80 \%$ of them agreeing that they enjoyed playing the board game, and that the game was a good way to train neonatal resuscitation (Figure 3). Since doctors and nurses enjoyed playing RETAIN, we think that they might be more motivated to practice their neonatal resuscitation knowledge and skills more often. 
Figure 2

We measured doctors' and nurses knowledge of the correct steps of neonatal resuscitation, using a pre-test before they played RETAIN and a post-test after they played. We discovered that doctors and nurses' test scores improved after playing the RETAIN board game. Important areas of knowledge are shown along the bottom of the graph, and the scores are shown by the blue bars.

Figure 3

Doctors and nurses liked playing the RETAIN board game, with $80 \%$ of them agreeing that they enjoyed playing RETAIN and that they thought it would be helpful for training in neonatal resuscitation.
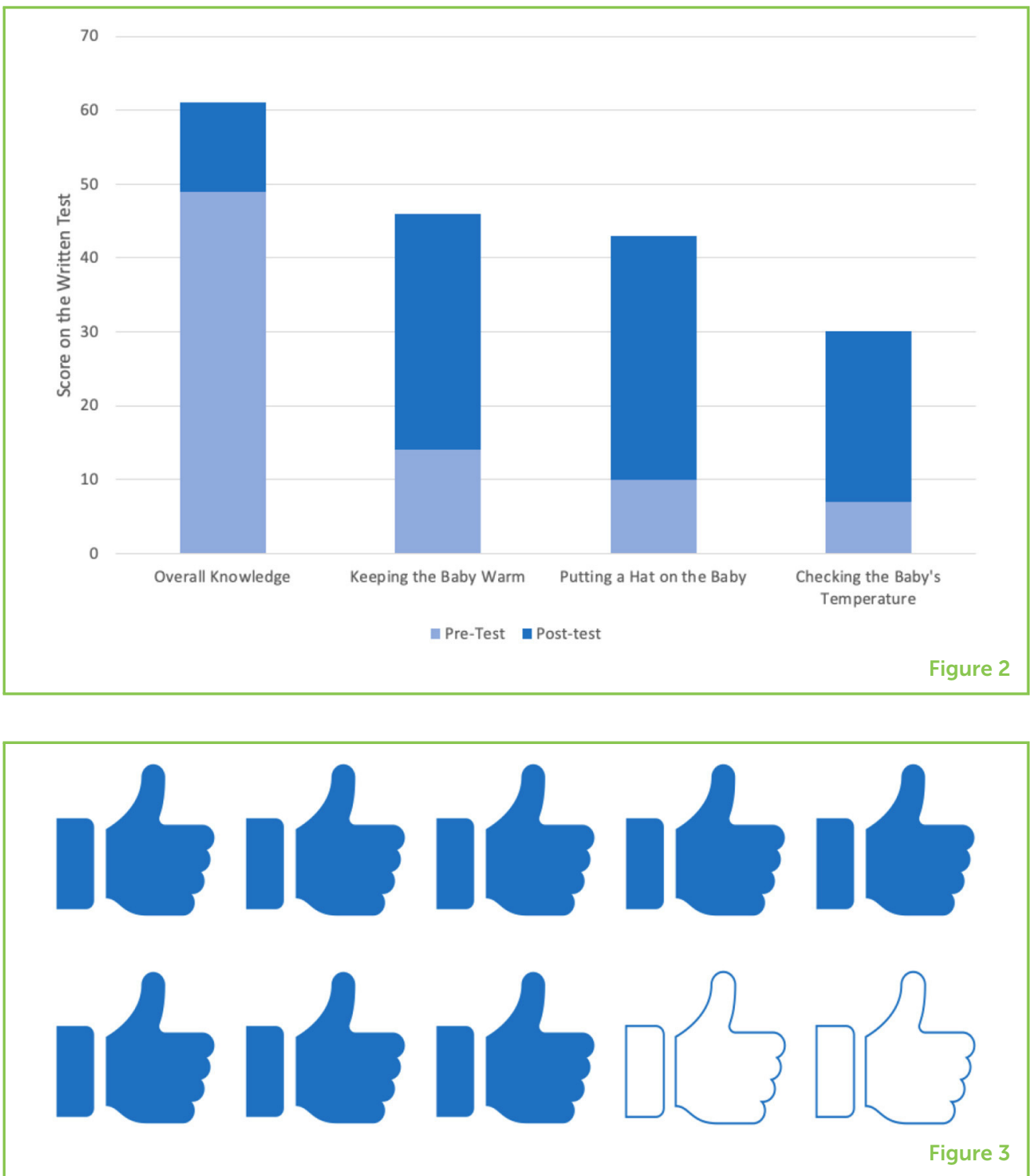

\section{WHAT ARE OUR NEXT STEPS?}

We showed that the RETAIN board game improves knowledge of neonatal resuscitation in doctors and nurses who have experience helping babies at birth. What we do not know is if RETAIN would also improve knowledge of neonatal resuscitation in less experienced doctors and nurses. We are currently conducting studies with less experienced doctors, nurses, paramedics, and midwives to understand if RETAIN also improves their neonatal resuscitation knowledge. We are also developing a video game and virtual reality version of RETAIN, which will allow doctors and nurses to practice their knowledge and skills of neonatal resuscitation in a different game format.

We know that simulation training is the best way for doctors and nurses to learn and practice their neonatal resuscitation knowledge. But simulation training takes a lot of time and money to organize, so 
many doctors and nurses do not get the training they need to provide the best care to their newborn patients. By making simulation training affordable and enjoyable for doctors and nurses, RETAIN may be the game-changing solution! If doctors and nurses can practice neonatal resuscitation more often, it will improve the lives of the newborn babies they care for. By continuing our research, we hope to make effective neonatal resuscitation training affordable and accessible to everyone helping babies at birth around the world. This is important, because all newborn babies deserve to receive the best quality care as they into enter the world and the loving arms of their families, triumphantly crying.

\section{SUGGESTED READING}

Want to know more? Take a look at some of the resources below, and get involved in clinical science research! Help us answer more questions about how to improve training for healthcare professionals, so that together we can give newborn babies the best start possible.

\section{AUTHOR CONTRIBUTIONS}

GS and SG: conception, literature search, drafting of the manuscript, critical revision of the manuscript, and final approval of the manuscript.

\section{ACKNOWLEDGMENTS}

We would like to thank the public for donating money to our funding agencies: SG was a recipient of the Maternal and Child Health Scholarship and the Department of Pediatrics Recruitment Scholarship (supported by the University of Alberta, Stollery Children's Hospital Foundation, Women and Children's Health Research Institute, and the Lois Hole Hospital for Women). GS was a recipient of the Heart and Stroke Foundation/University of Alberta Professorship of Neonatal Resuscitation, a National New Investigator of the Heart and Stroke Foundation Canada and an Alberta New Investigator of the Heart and Stroke Foundation Alberta.

\section{ORIGINAL SOURCE ARTICLE}

Cutumisu, M., Patel, S. D., Brown, M. R. G., Fray, C., von Hauff, P., Jeffery, T., et al. 2019. RETAIN: a board game that improves neonatal resuscitation knowledge retention. Front. Pediatr. 7:13. doi: 10.3389/fped.2019.00013 
SUBMITTED: 08 November 2019; ACCEPTED: 28 February 2020;

PUBLISHED ONLINE: 20 March 2020.

EDITED BY: Tansy C. Hammarton, University of Glasgow, United Kingdom

CITATION: Ghoman SK and Schmölzer GM (2020) Using Games to Train Doctors and Nurses to Save Babies at Birth. Front. Young Minds 8:31. doi: 10.3389/frym.2020. 00031

CONFLICT OF INTEREST: GS has registered the RETAIN board game [Tech ID 2017083] under Canadian copyright [Tech ID 2017086] and one of the owners of RETAIN Labs Medical Inc., Edmonton, Canada (https://www.playretain.com) which is distributing the game.

The remaining author declares that the research was conducted in the absence of any commercial or financial relationships that could be construed as a potential conflict of interest.

COPYRIGHT @ 2020 Ghoman and Schmölzer. This is an open-access article distributed under the terms of the Creative Commons Attribution License (CC BY). The use, distribution or reproduction in other forums is permitted, provided the original author(s) and the copyright owner(s) are credited and that the original publication in this journal is cited, in accordance with accepted academic practice. No use, distribution or reproduction is permitted which does not comply with these terms.

\section{YOUNG REVIEWER}

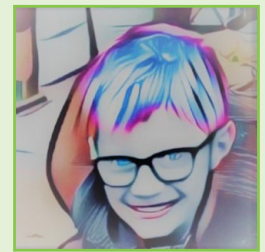

\section{EDWARD, AGE: 12}

Edward is a 12 years old boy who likes art and is fascinated by science. He likes to pass time by watching YouTube and playing on his Nintendo Switch. In the future he would like to become a computer engineer or technician.

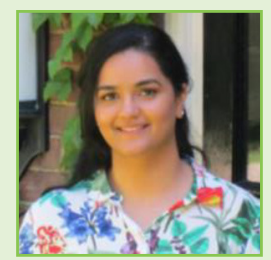

\section{AUTHORS}

\section{SIMRAN K. GHOMAN}

Simran K. Ghoman is a Master of Science candidate in pediatric/neonatal medicine, with an interest in improving healthcare access and delivery in limited-resource settings.

\section{GEORG M. SCHMÖLZER}

Georg M. Schmölzer is a research neonatologist, focused on better understanding what changes a baby go through during birth with special emphasis on improving the quality of life for newborn babies. *georg.schmoelzerame.com 